Hawker, L. E., Hepden, P. M. \& Perkins, S. M. (1957). J. gen. Microbiol. 17,758-767

\title{
The Inhibitory Effect of Low Temperature on Early Stages of Zygospore Production in Rhizopus sexualis
}

\author{
By LILIAN E. HAWKER, PAMELA M. HEPDEN AND \\ SHEILA M. PERKINS
}

Department of Botany, University of Bristol

SUMMARY: Colonies of Rhizopus sexualis (Smith) Callen on $1 \%(\mathrm{w} / \mathrm{v})$ malt agar at $20^{\circ}$ show the first stages in conjugation approximately $40 \mathrm{hr}$. after inoculation and the first mature zygospores after a further $32-34 \mathrm{hr}$. Transfer to $5-10^{\circ}$ prevents the initiation of conjugation and inhibits the further development of the majority of pairings in which the gametangia are not fully delimited at the time of transfer. Fully delimited gametangia continue to develop and to produce mature zygospores at the low temperature. This effect is almost entirely independent of the composition and $\mathrm{pH}$ value of the medium. Sporangia are produced in greater numbers at the low temperature than at $20^{\circ}$. The effect of low temperature on formation of zygospores of Mucor hiemalis, Zygorrhynchus macrocarpus and Z. moelleri is essentially similar to that with $R$. sexualis, but Phycomyces blakesleeanus shows only slight inhibition at $5^{\circ}$ and none at $7^{\circ}$ or over. The significance of the inhibitory effect is discussed.

When cultures of Rhizopus sexualis (Smith) Callen (a homothallic species of the Mucoraceae) showing all stages in zygospore formation were stored at $7^{\circ}$ most of the young zygospores continued to develop and reached maturity, although the rate of development was decreased by the low temperature. Early stages in conjugation already present on transfer to low temperature did not result in zygospores and no further conjugations took place. When the cultures were replaced at $20^{\circ}$ conjugations again took place. It was hoped that further study might elucidate the mechanism of the particular stage in reproduction at which the inhibitory effect of low temperature was most marked.

The literature relating to the general effect of temperature on growth and reproduction in fungi has been reviewed (Hawker, 1950, 1957; Lilly \& Barnett, 1951). Although there is little detailed information about the effects of temperature on zygospore formation in the Mucoraceae, the available information shows that these effects are complex. Zygospore production by Sporodinia grandis ( = Syzygites megalocarpa) is favoured by higher temperatures than those optimal for sporangial production (Baker, 1931). Zygospores of Thamnidium elegans are formed only after exposure to temperatures of $6-7^{\circ}$ (Hesseltine \& Anderson, 1956). Robins \& Schmitt (1945) showed that temperature influences zygospore formation by Phycomyces blakesleeanus by an indirect effect on hydrogen-ion concentration.

The type of asexual reproduction in pleomorphic members of the Mucoraceae is controlled by the interaction of a number of factors, including temperature. 
A striking example is Choanephora cucurbitarum (Barnett \& Lilly, 1950); at $25^{\circ}$ conidia are formed more frequently than sporangia, at $30^{\circ}$ sporangia predominate and at $31^{\circ}$ only sporangia are formed.

\section{METHODS}

Material. The strain of Rhizopus sexualis used was derived from the original isolate from strawberry (Smith, 1938; Callen, 1940). Other species used (homothallic species, Zygorrhynchus macrocarpus, Z. moelleri; heterothallic species, Mucor hiemalis, Phycomyces blakesleeanus) were taken from the collection in this Department. All organisms were maintained on malt agar slopes.

Culture methods. Unless otherwise stated, the cultures were grown on $1 \%$ (w/v) malt agar, since this medium at suitable temperatures allowed the formation of a moderate number of zygospores without the development of sufficient aerial mycelium to make observations difficult. Plate cultures (in Petri dishes, $9 \mathrm{~cm}$. diameter) were inoculated with disks, $7 \mathrm{~mm}$. diameter, cut from the advancing edges of young colonies before conjugation had begun, thus ensuring that no young zygospores were included in the inoculum. Slide cultures, in which microscope slides were coated with a film of agar medium and supported on glass rods in damp sterile Petri dishes, were inoculated with smaller pieces of young agar cultures.

\section{Estimation of growth and reproduction}

Mycelial growth. The average diameter of colonies was measured at suitable intervals.

Zygospore counts. With plate cultures of Rhizopus sexualis lines at right angles through the centre of the inoculum were marked on the bottom of the plate. Arbitrarily chosen points were marked along these lines and the number and stage of development of the zygospores in microscopic fields at these points were recorded at intervals. Microscopic fields at arbitrarily determined points were also examined in slide cultures. These methods were not entirely suitable for use with the other species studied. Zygospores of Zygorrhynchus spp. are small and crowded and counts can be made only on slide cultures. With the plate cultures the sharply demarcated central zone containing zygospores was outlined in Indian ink on the base of the Petri dish before transfer to low temperature and any further conjugations seen beyond this outline were later recorded.

The heterothallic Mucor hiemalis also produces small crowded zygospores along the line of contact of the 'plus' and 'minus' colonies and aerial mycelium along this zone is profuse. It was possible to count the zygospores at various stages of development along a short arbitrarily chosen part of the zone.

Zygospores of Phycomyces blakesleeanus are so large that the total number on a plate could be recorded. 
Definition of stages in development of zygospores

A. Early progametangial stage: progametangia just recognizable, slightly swollen (Fig. 1 A).

B. Progametangial stage: progametangia much enlarged, cytoplasm denser than in supporting hyphae (Fig. 1B).

C. Early gametangial stage: gametangia distinguishable but not cut off by cross-walls (Fig. $1 \mathrm{C}$ ).

D. Gametangial stage: gametangia delimited by cross-walls (Fig. 1D).

E. Fusion stage: wall between gametangia dissolved, no dark pigment (Fig. 1E).

F. Young zygospore stage: spore rounded-off, enlarged, brown pigment present, warty thickenings developing on wall (Fig. 1 F).

G. Mature zygospore stage: spore further enlarged, black, well-developed warts on wall (Fig. 1 G).
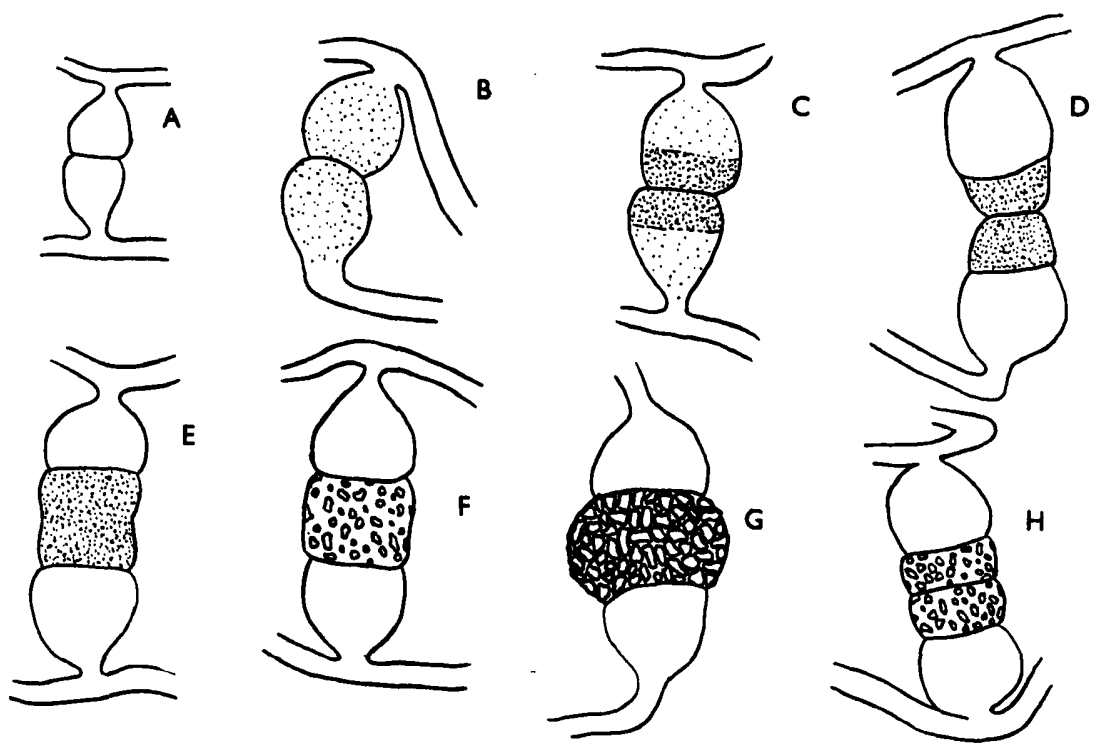

Fig. 1. Formation of zygospores of Rhizopus sexualis. A=early progametangial stage; $\mathbf{B}=$ progametangial stage; $\mathbf{C}=$ early gametangial stage; $\mathbf{D}=$ gametangial stage; $\mathbf{E}=$ fusion stage $; \mathbf{F}=$ young zygospore $; \mathbf{G}=$ mature zygospore $; \mathbf{H}=$ abnormal zygospore in which wall between gametangia has failed to dissolve (stage $X$ in text, p. 760). A-H, $\times \mathbf{8 0}$.

Occasionally the gametangia were delimited normally (stage $\mathrm{D}$ ) but the wall between them did not break down. Various degrees of pigmentation and sculpturing of the gametangial wall followed, but normal zygospores were not produced. All such abnormal forms were recorded as $\mathrm{X}$ (Fig. 1H).

The description of the stages given above refers to Rhizopus sexualis, but the scheme was also valid for the other species used, due allowance being made for differences in type of wall sculpture, presence of bristles as outgrowths of the suspensor cells (in Phycomyces blakesleeanus), etc. 
Zygospore index. In order to assess the general stage of zygospore production reached by a particular colony, an arbitrary Zygospore Index (ZI) was calculated. The stages $A-G$ were given an arbitrary value of 1-7 respectively. The total number of pairings at any particular stage seen in the microscopic fields chosen as indicated above, was multiplied by the figure allotted to that stage and these results were summed to give a value for $\mathbf{Z I}$.

\section{RESULTS}

Production of zygospores by Rhizopus sexualis at $20^{\circ}$

Progametangia (stages A and B) developed at the centre of colonies of Rhizopus sexualis on malt agar at $20^{\circ}$ about $40 \mathrm{hr}$. after inoculation. Delimitation of the gametangia (stages $\mathrm{C}$ and $\mathrm{D}$ ) took place 8-10 hr. later and a few mature zygospores (stage $\mathrm{G}$ ) were present after a further $24 \mathrm{hr}$., i.e. approximately 72-74 hr. after inoculation (Table 1, column 6).

Table 1. The effect of temperature on growth and zygospore formation in Rhizopus sexualis

Treatments I-V, transferred from $20^{\circ}$ to $7^{\circ}$ at $24,28,32.5,43.5$ and $50.5 \mathrm{hr}$. after inoculation, respectively. The entries in heavy type indicate the time at which transfer was made. Treatment VI, kept at $20^{\circ}$ throughout experiment.

Figures represent average diameter $(\mathrm{cm}$.) of colonies. $(\mathrm{f})=$ flat colony, hyphae creeping on surface of medium. (a) = upright aerial hyphae present.

A-G represent stages in development of zygospores (see Fig. 1), coefficients are numbers of each stage present in arbitrarily selected microscopic fields (see p. 759,760$)$.

$\mathbf{P}=$ total number of pairings in these fields.

$\mathbf{Z I}=$ quantitative index of zygospore production (see p. 761).

\begin{tabular}{|c|c|c|c|c|c|c|}
\hline \multirow{2}{*}{$\begin{array}{c}\text { Period after } \\
\text { inoculation } \\
\text { (hr.) }\end{array}$} & \multicolumn{6}{|c|}{ Treatments } \\
\hline & I & II & III & IV & $\mathbf{V}$ & VI \\
\hline \begin{tabular}{l|}
24 \\
28 \\
$32 \cdot 5$ \\
$43 \cdot 5$
\end{tabular} & $\begin{array}{l}2 \cdot 7 \text { (f) } \\
2 \cdot 7 \text { (f) } \\
2.9 \text { (f) } \\
3.0 \text { (f) }\end{array}$ & $\begin{array}{l}2 \cdot 7 \text { (f) } \\
2 \cdot 9 \text { (f) } \\
3 \cdot 0 \text { (f) } \\
3 \cdot 3 \text { (f) }\end{array}$ & $\begin{array}{l}2 \cdot 6(f) \\
3 \cdot 0 \text { (f) } \\
3 \cdot 4(a) \\
3 \cdot 7(a)\end{array}$ & $\begin{array}{c}2 \cdot 6(\mathrm{f}) \\
2 \cdot 9(\mathrm{f}) \\
3 \cdot 3(\mathrm{a}) \\
4 \cdot 5(\mathrm{a}) \\
(15 \mathrm{~A}, 11 \mathrm{~B}, 2 \mathrm{C}, \\
2 \mathrm{D}, 1 \mathrm{E}, 5 \mathrm{~F}) \\
\mathrm{P}=36 \\
\mathrm{ZI}=86\end{array}$ & $\begin{array}{c}2.7(f) \\
2 \cdot 9(f) \\
3.8(\mathrm{a}) \\
4.6(\mathrm{a}) \\
(8 \mathrm{~A}, 14 \mathrm{~B}, \mathbf{3 C}, \\
\mathbf{2 D}, \mathbf{1 E}, 4 \mathrm{~F}) \\
\mathbf{P}=\mathbf{3 2} \\
\mathrm{ZI}=\mathbf{8 2}\end{array}$ & 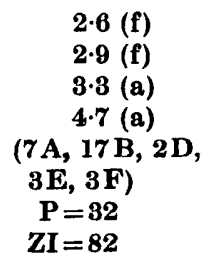 \\
\hline $50 \cdot 5$ & $3 \cdot 1(f)$ & $3 \cdot 4(f)$ & $3 \cdot 9(a)$ & $\begin{array}{c}4 \cdot 7(\mathrm{a}) \\
(10 \mathrm{~A}, 10 \mathrm{~B}, 3 \mathrm{C} \\
3 \mathrm{D}, 4 \mathrm{E}, 7 \mathrm{~F}) \\
\mathrm{P}=37 \\
\mathrm{ZI}=113\end{array}$ & $\begin{array}{c}5 \cdot 3(\mathrm{a}) \\
(3 \mathrm{~A}, 13 \mathrm{~B}, 4 \mathrm{C} \\
2 \mathrm{D}, 4 \mathrm{E}, 20 \mathrm{~F}) \\
\mathrm{P}=46 \\
\mathrm{ZI}=189\end{array}$ & $\begin{array}{c}5.4(\mathrm{a}) \\
(1 \mathrm{~A}, 4 \mathrm{~B}, 13 \mathrm{C} \\
3 \mathrm{D}, 17 \mathrm{~F}) \\
\mathrm{P}=\mathbf{3 8} \\
\mathrm{ZI}=168\end{array}$ \\
\hline $67 \cdot 5$ & $3 \cdot 2(f)$ & $3 \cdot 5(f)$ & $4 \cdot 0(a)$ & $\begin{array}{c}4.9(\mathrm{a}) \\
(9 \mathrm{~A}, 3 \mathrm{BB}, 2 \mathrm{C} \\
3 \mathrm{D}, 2 \mathrm{E}, 11 \mathrm{~F}, \\
7 \mathrm{G}) \\
\mathrm{P}=\mathbf{3 7} \\
\mathrm{ZI}=158\end{array}$ & $\begin{array}{l}5 \cdot 5(\mathrm{a}) \\
(3 \mathrm{~A}, 8 \mathrm{~B}, 1 \mathrm{C} \\
1 \mathrm{D}, 7 \mathrm{E}, 18 \mathrm{~F}, \\
7 \mathrm{G}) \\
\mathrm{P}=45 \\
\mathrm{ZI}=217\end{array}$ & $\begin{array}{c}7 \cdot 4(\mathrm{a}) \\
(6 \mathrm{~A}, 24 \mathrm{~B}, 5 \mathrm{C}, \\
4 \mathrm{D}, 5 \mathrm{E}, 33 \mathrm{~F}, \\
1 \mathrm{G}) \\
\mathbf{P}=78 \\
\mathrm{ZI}=\mathbf{8 1 5}\end{array}$ \\
\hline $119 \cdot 5$ & 3.5 (f) & $3 \cdot 8$ (f) & $4 \cdot 15$ (a) & $\begin{array}{c}5 \cdot 0(\mathrm{a}) \\
(9 \mathrm{~A}, 3 \mathrm{~B}, 8 \mathrm{~F} \\
17 \mathrm{G}) \\
\mathrm{P}=\mathbf{3 7} \\
\mathrm{ZI}=182\end{array}$ & 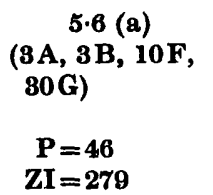 & $\begin{array}{c}9 \cdot 0(\mathrm{a}) \\
(4 \mathrm{~A}, 7 \mathrm{~B}, 4 \mathrm{C} \\
6 \mathrm{D}, 6 \mathrm{E}, 16 \mathrm{~F}, \\
64 \mathrm{G}) \\
\mathrm{P}=107 \\
\mathrm{ZI}=628\end{array}$ \\
\hline
\end{tabular}


Transfer to low temperature at various intervals after inoculation

In a typical experiment, 18 malt agar plates were given a preliminary incubation at $20^{\circ}$. Batches of three plates were transferred to $7^{\circ}$ after 24,28 , $32.5,43.5$ and $50.5 \mathrm{hr}$., respectively. Table 1 shows diameter of colonies, type of growth, total numbers of conjugations $(P)$, numbers of conjugations at each stage (Fig. 2) and the zygospore index (ZI), at intervals during the experiment.

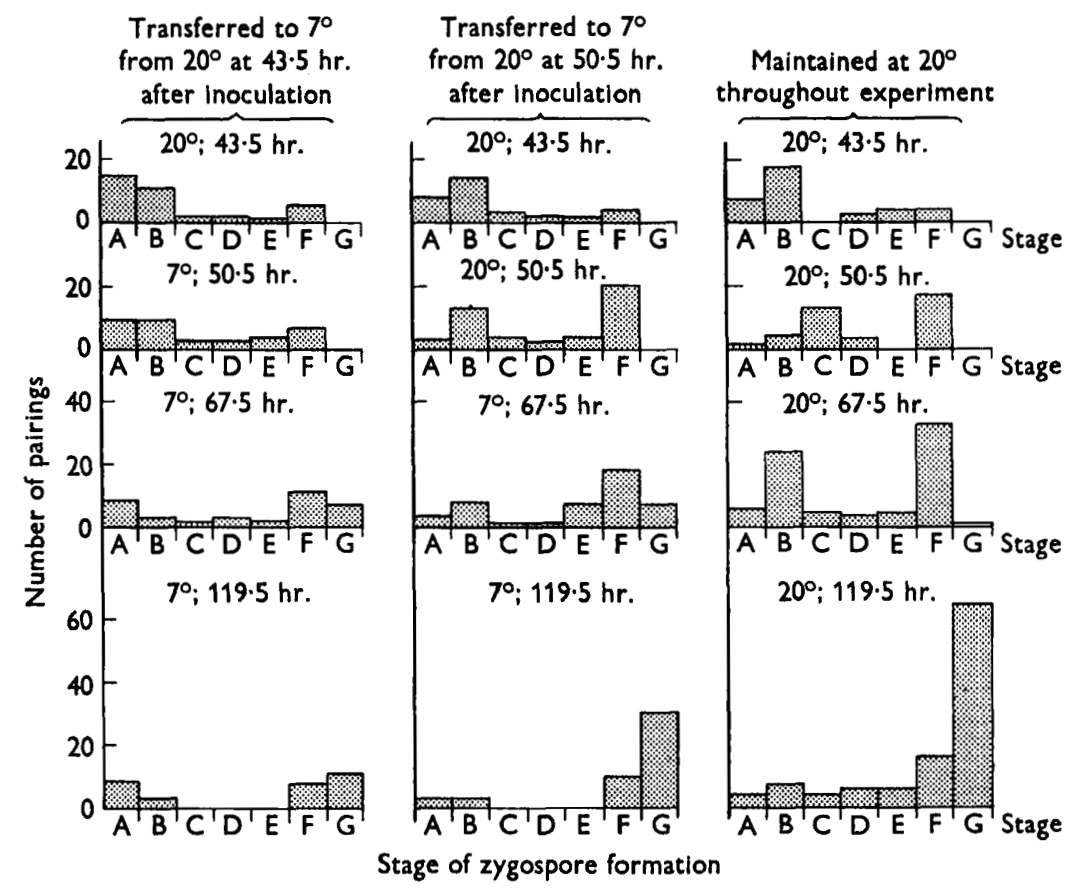

Fig. 2. Effect of transfer from $20^{\circ}$ to $7^{\circ}$ on development of zygospores of Rhizopus sexualis. Each block represents number of zygospores at the particular stage A-G (Fig. 1) at intervals after inoculation.

No gametangial initials developed after transfer to $7^{\circ}$ in any culture on which they were not already present at the time of transfer, i.e. treatments I, II and III of Table 1. Even where (as in cultures subjected to treatment III) aerial hyphae, which would have borne gametangia if left at $20^{\circ}$, had already developed, no conjugations took place at the low temperature. In colonies transferred at a later stage, i.e. treatments IV and V, conjugation had already begun. Zygospores which had reached stage $\mathrm{C}$, or a later stage, continued to develop at $7^{\circ}$, but only a few of those at earlier stages reached the next one. These few were presumably already physiologically near the next stage of development. In other experiments the effect of transfer of colonies from $20^{\circ}$ to $5^{\circ}, 10^{\circ}$ and $11.5^{\circ}$ was studied. Fig. 3 shows the fate of particular pairs of progametangia or gametangia as a result of these treatments. 
The results of these experiments and of experiments with slide cultures may be summarized as follows:

(1) The formation of aerial hyphae which normally precedes zygospore formation is inhibited at low temperatures. Aerial hyphae which have already formed continue to develop.
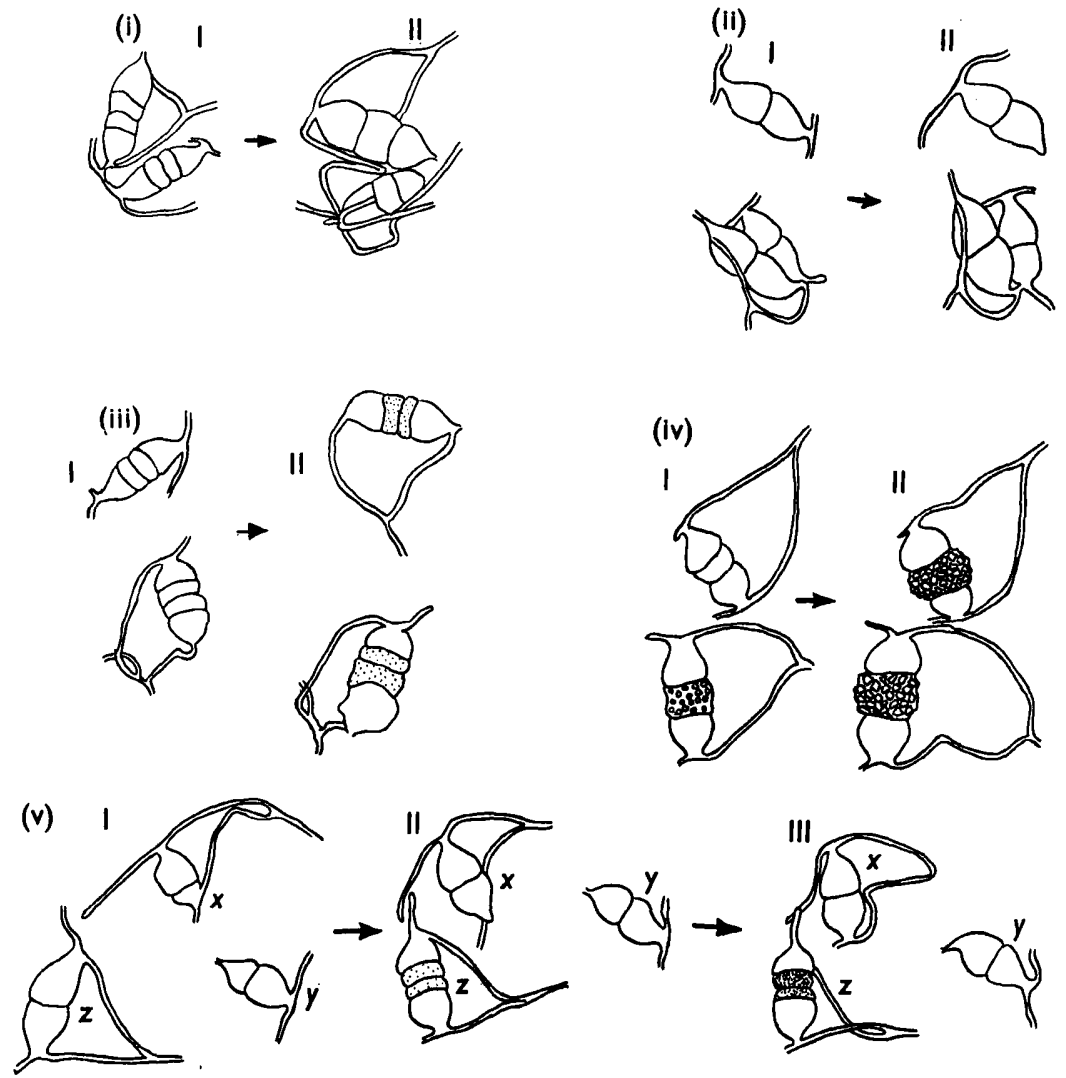

Fig. 3. Effect of exposure to $10^{\circ}$ on formation of zygospores by Rhizopus sexualis. (i), (ii), (iii) and (iv), the condition of pairs of progametangia and gametangia: I, immediately before transfer to $10^{\circ}$; II, $48 \mathrm{hr}$. later. $\times 45$. (v) Three pairs of progametangia, $x, y$ and $z$ : I, before transfer to $10^{\circ}$; II, after $24 \mathrm{hr}$. at $10^{\circ}$; III, after a further $48 \mathrm{hr}$. at $10^{\circ}$. $\times 45$.

(2) Gametangia are not formed at $5-10^{\circ}$ unless visible progametangial initials are present when the colonies are transferred to the low temperature, i.e. low temperature prevents the initiation of conjugation. Temperatures of $11.5^{\circ}$ and over do not inhibit the formation of progametangia.

(3) Progametangia (stages $A$ and B) present on colonies at the time of transfer do not develop further at $5^{\circ}$, but may occasionally do so at $7^{\circ}$ or $10^{\circ}$. This tendency to continue development is increased in the presence of mature zygospores at the time of transfer (see columns IV and V of Table 1). Progametangia continue to develop normally at temperatures of $11 \cdot 5^{\circ}$ and higher. 
(4) When stages $C$ and $D$ have been reached before transfer to low temperature, development usually continues at a decreased rate. Abnormal zygospores (stage $\mathrm{X}$, Fig. 1H) increase in frequency with decrease in temperature.

(5) When colonies which have been exposed to low temperature are restored to $20^{\circ}$, development of initials already present and initiation of new progametangia are resumed, showing that the low temperature produces only a temporary inhibition of zygospore initiation and development.

(6) Sporangia are produced regularly but sparsely at $20^{\circ}$. After about 3 weeks at low temperature, sporangia are abundant and their formation is independent of the presence of zygospores.

\section{The effect of brief exposures to $20^{\circ}$}

It seemed possible that exposure to higher temperatures for the time needed to make observations in the experiments described in the previous section might have influenced results. This was tested by exposing cultures to a temperature of $20^{\circ}$ for varying intervals during cold treatment. It was found that the low-temperature effect was not reversed by less than $4 \mathrm{hr}$. at $20^{\circ}$.

The effective time of exposure to $20^{\circ}$ varies according to the age of the colony. When aerial hyphae are present whilst the colony is still at low temperature, exposure for $4 \mathrm{hr}$. to $20^{\circ}$ is sufficient to initiate a few young stages. These do not mature when the cultures are replaced at low temperature but develop only as far as stage $X$. A longer time at $20^{\circ}$ is required between the cold periods for fully mature zygospores to result. Exposure for $8 \mathrm{hr}$. at $20^{\circ}$, followed by resumed cold treatment, resulted in a number of zygospores which ultimately matured at low temperature. Exposure for $12 \mathrm{hr}$. to $20^{\circ}$ gave similar results, with a great increase in the number of zygospores as compared with those formed on colonies given $8 \mathrm{hr}$. at $20^{\circ}$.

Continuous exposure to $20^{\circ}$ after cold treatment frequently results in rapid development of, or increase in, aerial hyphae on that part of the colony which grew before or during cold treatment. This suggests that some product accumulates at low temperature and becomes available on return to $20^{\circ}$, resulting in this great aerial growth.

Clearly there is no permanent effect of cold treatment on the fungus. Hyphal tips from cultures grown at $7^{\circ}$ were subcultured and incubated at $20^{\circ}$, when they showed a growth rate comparable to that of tips from cultures grown at $20^{\circ}$.

\section{The influence of composition and $\mathrm{pH}$ value of the medium on the response of Rhizopus sexualis to low temperatures}

In addition to the $1.0 \%(\mathrm{w} / \mathrm{v})$ malt extract agar used for most experiments, the following agar media were tested: $2 \cdot 0,3 \cdot 0$ and $5 \cdot 0 \%(w / v)$ malt, yeast extract, carrot extract, prune extract, glucose + asparagine, glucose +ammonium salts and glucose peptone. The time for progametangial initials to appear, and the time for mature zygospores to develop varied considerably with different media at $20^{\circ}$. Inhibition of early stages of zygospore formation occurred at low temperatures on all the media tested, as on malt agar, but with 
carrot extract agar there was a slight increase in the number of young stages which continued to develop at low temperature.

It seemed possible that low temperature might act by influencing changes in the $\mathrm{pH}$ value of the medium. Rhizopus sexualis forms zygospores over the range $3 \cdot 0-8 \cdot 0$ of initial $\mathbf{p H}$ values. Varying the initial $\mathrm{pH}$ value of the medium over this range did not prevent the inhibition of initiation and early development of zygospores at low temperatures.

\section{The effect of low temperature on other species}

Phycomyces blakesleeanus. No inhibition of initiation or maturation of zygospores occured at $7^{\circ}$, or higher, but exposure to $5^{\circ}$ decreased the number of new progametangia which arose (Table 2).

Table 2. The effect of low temperature on zygospore production in five species of the Mucorales

The colonies were incubated at $20^{\circ}$ until they had reached the stages indicated in the column headings and were then transferred to the low temperature. The results given were obtained after 4 days at the low temperature.

The first symbol in each column refers to the degree of inhibition of new progametangia, the second refers to the degree of inhibition of further development and maturation of conjugations which had reached stages $\mathrm{A}-\mathrm{C}$ at the time of transfer. $0=$ complete inhibition; $(0)=$ occasional initiation of new progametangia; $(+)=$ development continues but is not completed; $(X)=$ occasional production of abnormal zygospores; $+=$ no inhibition.

\begin{tabular}{|c|c|c|c|c|}
\hline \multirow[b]{2}{*}{ Species } & \multicolumn{4}{|c|}{$\begin{array}{c}\text { Condition of colony on transfer } \\
\text { to low temperature }\end{array}$} \\
\hline & \multirow{2}{*}{\multicolumn{2}{|c|}{$\begin{array}{l}\text { No mature } \\
\text { zygospores }\end{array}$}} & \multicolumn{2}{|c|}{$\begin{array}{l}\text { Mature zygospores } \\
\text { present }\end{array}$} \\
\hline Temperature $5^{\circ}$ & & & & \\
\hline Rhizopus sexualis & 0 & $\mathbf{0}(\mathbf{X})$ & $\mathbf{0}$ & + \\
\hline Mucor hiemalis & $\mathbf{0}$ & $\mathbf{0}$ & $\mathbf{0}$ & + \\
\hline Zygorrhynchus macrocarpus & $\mathbf{0}$ & $\mathbf{0}$ & $\mathbf{0}$ & $(+)$ \\
\hline Z. moelleri & $\mathbf{0}$ & $\mathbf{0}$ & $\mathbf{0}$ & $(+)$ \\
\hline Phycomyces blakesleeanus & (0) & + & + & + \\
\hline \multicolumn{5}{|l|}{ Temperature $7^{\circ}$} \\
\hline Rhizopus sexualis & $\mathbf{0}$ & + & $\mathbf{0}$ & + \\
\hline Mucor hiemalis & $\mathbf{0}$ & $\mathbf{0}(\mathbf{X})$ & $\mathbf{0}$ & + \\
\hline Zygorrhynchus macrocarpus & $\mathbf{0}$ & $(+)$ & $\mathbf{0}$ & + \\
\hline Z. moelleri & (0) & + & (0) & + \\
\hline Phycomyces blakesleeanus & + & + & + & + \\
\hline \multicolumn{5}{|l|}{ Temperature $10^{\circ}$} \\
\hline Rhizopus sexualis & $\mathbf{0}$ & + & (0) & + \\
\hline Mucor hiemalis & + & + & + & + \\
\hline Zygorrhynchus macrocarpus & + & + & + & + \\
\hline Z. moelleri & + & + & + & + \\
\hline Phycomyces blakesleeanus & + & + & + & + \\
\hline
\end{tabular}

Mucor hiemalis. Zygospores were not produced at $5^{\circ}$ or $17^{\circ}$ when conjugation had not taken place before transfer to the low temperatures, but when older stages were present before transfer, zygospores developed from pre-existing initials (stage $\mathrm{B}$ for $7^{\circ}$, stage $\mathrm{D}$ for $5^{\circ}$ ). No new progametangia were initiated 
at $7^{\circ}$ or $5^{\circ}$. There was no inhibition of initiation or development at $10^{\circ}$ (Table 2).

Zygorrhynchus macrocarpus. At $5^{\circ}$ initiation and maturation of progametangia and zygospores was inhibited unless a number of mature zygospores were present, in which case pre-existing progametangia (stage B) developed until partially mature but did not attain full maturity, reaching only stage $\mathrm{F}$, with some pigmentation. At $7^{\circ}$ initiation was similarly inhibited, but pre-existing conjugation matured as far as stage $F$ only. When a number of mature zygospores were present, however, the development of younger ones continued to full maturity. There was no inhibition of initiation or development at $10^{\circ}$ (Table 2).

Zygorrhynchus moelleri. Initiation of progametangia never occurred at $5^{\circ}$ and rarely at $7^{\circ}$. At $5^{\circ}$ pre-existing conjugations (stage $B$ ) continued to develop but did not mature completely, whilst at $7^{\circ}$ maturation was eventually completed at the low temperature. No inhibition occurred at $10^{\circ}$.

\section{DISCUSSION}

It is clear that, while the whole process of conjugation and zygospore formation is slowed by a lowering of temperature below the optimum, the effect of low temperatures is greatest at certain early stages in this process. The actual temperature at which inhibition of conjugation and zygospore development occurs varies with the species but the differential effect of temperature on early stages was seen in all five species examined. This greater sensitivity to low temperature at early stages in zygospore development suggests either a temperature-induced block in the synthesis of some substance or substances essential to further development, or a slowing of translocation of such substances into the gametangia from the supporting hyphae.

Under some circumstances the presence of mature zygospores in a colony at the time of exposure to the critical low temperature enables the continued development of young spores which would otherwise have been checked. Work now in progress indicates that this effect of mature zygospores is due to a substance or substances which diffuses from them. It is suggested that this may be identical with, or able to replace, an essential substance the synthesis of which is inhibited by low temperature. The effect of low temperature is thus more likely to be due to the inhibition of synthesis rather than a retardation of diffusion or translocation. The nature of the inhibitory effect of low temperature is being further examined.

\section{REFERENCES}

BAKER, R. E. D. (1931). Spore formation in Sporodonia grandis (Link.). New Phytol. 30, 303.

BarnetT, H. L. \& Lilly, V. G. (1950). Nutritional and environmental factors influencing asexual sporulation of Choanephora cucurbiratum in culture. Phytopathology, 40, 80.

Callen, E. O. (1940). Morphology, cytology and sexuality of the homothallic Rhizopus sexualis (Smith) Callen. Ann. Bot., Lond. N.S. 4, 791. 
Hawker, L. E. (1950). Physiology of Fungi. University of London Press.

Hawker, L. E. (1957). The Physiology of Reproduction in Fungi. Cambridge Monographs in Experimental Biology. Cambridge University Press.

Hesseltine, C. W. \& Anderson, P. (1956). The genus Thamnidium and a study of the formation of its zygospores. Amer. J. Bot. 43, 696.

Lilly, V. G. \& Barnetr, H. L. (1951). Physiology of the fungi. New York: McGraw Hill.

Robbins, W. J. \& Schmitr, M. B. (1945). Factor $\mathrm{Z}_{2}$ and gametic reproduction by Phycomyces. Amer. J. Bot. 32, 320.

Sмrт, G. (1938). New species of mould fungi. Mucor sexualis. Trans. Brit. mycol. Soc. 22, 252.

(Received 15 July 1957) 